\title{
Exploring the medication duration based on the effect of traditional Chinese medicine on postoperative stage I-III colorectal patients: a retrospective cohort study
}

\author{
Qi Shi ${ }^{1, *}$, Shanshan Liuu, ${ }^{1,}$, Wen $\mathrm{Li}^{1}$, Shaoqi Zong ${ }^{1}$, Susu Han ${ }^{1}$, Wei Yang ${ }^{1}$, Hongjia $\mathrm{Li}^{1}$, \\ Fenggang Hou ${ }^{1}$ \\ ${ }^{1}$ Oncology Department of Municipal Hospital of Traditional Chinese Medicine, Shanghai University of Traditional Chinese \\ Medicine, Shanghai 200071, China \\ *These authors are contributed equally to this work
}

Correspondence to: Fenggang Hou, email: fghou555@126.com

Hongjia Li, email: Ihjmaomaochong@163.com

Keywords: colorectal cancer, medication duration, traditional Chinese medicine

Received: November 25, $2016 \quad$ Accepted: December 27, $2016 \quad$ Published: January 09, 2017

ABSTRACT

Purpose: To clarify the effect of tradional Chinese medicine (TCM) on different stage patients and to explore medication duration based on survival analysis.

Results: 523 and 294 patients were respectively in the TCM group and the control group. For all patients, 6-year disease-free survival (DFS) was $57.6 \%$ after TCM and $46.6 \%$ after non-TCM $(p=0.0006)$. 6-year DFS for patients with stage I disease in the TCM group was $79.5 \%$ compared with $89.1 \%$ in the control group $(p=0.65)$. For patients with stage II disease, 6 -year DFS was $63.1 \%$ in the TCM group compared with $50.2 \%$ in the control group $(p=0.054)$, and for patients with stage III disease, it was $43.3 \%$ in the TCM group compared with $22.0 \%$ in the control group $(p=0.0000)$.

Materials and Methods: Data for patients with stage I-III disease between 2004 and 2013 were retrieved for this study, who underwent TCM after surgery were in the TCM group and the others were in the control group. Clinic appointments or phone were used to collect data by research assistants. Survival data were collected on Nov $\mathbf{2 0 1 5}$ from the database, which is continuously updated by the researchers.

Conclusions: TCM is associated with significantly improved disease-free survival, in particular for patients with stage III disease. Among of these, TCM is not necessary for patients with stage I disease, and postoperative patients with stage II disease should be recommended to take 2 years of TCM. For patients with stage III disease, adherence to medication of TCM during the 6-year follow-up is worthy of being recommended.

\section{INTRODUCTION}

Colorectal cancer (CRC) is one of the most common malignant tumors [1-3].Surgery is still the main treatment of CRC, but approximately $35 \%$ of patients develop to recurrence [4].Traditional Chinese medicine (TCM) play an important role in adjuvant therapy. Two study summarized that TCM had three advantages to prevent and treat tumor: preventing tumorigenesis; attenuating toxicity and enhancing the treatment effect; and reducing risk of recurrence and metastasis $[5,6]$. In previous studies, we found TCM could reduce the risk of metastatic recurrence of patients with $\mathrm{CRC}$, and prolong the diseasefree survival (DFS) [7-9], which was in agreement with other studies [10-13]. However, whether TCM can all reduce the recurrence risk for patients with different stage disease is still unknown. In addition, treatment duration of TCM is too long, and this is one of the main reasons for patients to interrupt the treatment. How long should patients receive TCM treatment?

Therefore, we undertook this study in order to clarify the effect of TCM on patients with different stage disease and to provide evidence on the patients' medication duration.

\section{RESULTS}

Baseline characteristics

817 patients were included in this cohort study. Table 1 shows the baseline and tumor characteristics. 
In the TCM group, $461(88.1 \%)$ of 523 patients with adenocarcinoma compared with 236 of 294 (80.3\%) in the control group. $(p=0.01)$. In addition, difference of histodifferentiation between two groups was significant $(p=0.01) .420(80.3 \%)$ of 523 patients received adjuvant chemotherapy in the TCM group and 204 (69.4\%) of 294 patients in the control group $(p=0.000)$. The baseline characteristics after propensity score matching was shown in Supplementary Table 1. Meanwhile, results of multiple factor analysis were shown in Supplementary Table 2. Among of them, hazard ratio (HR) of TCM was 1.67 and $95 \%$ CI was 1.33 to 2.11. Follow-up in the TCM group with a median of 55.6 months compared with 40.8 months in the control group $(p=0.16)$.

\section{Effect of TCM on all stage I-III CRC patients}

1-6 year disease-free survival in the TCM group were $95.6 \%, 79.0 \%, 69.6 \%, 63.6 \%, 60.9 \%$ and $57.6 \%$. Those in the control group were $84.6 \%, 67.1 \%, 58.7 \%$, $53.9 \%, 52.5 \%$ and $46.6 \%$ (Supplementary Figure 1). In Figure 1, the result of median disease-free survival (mDFS) in the control group was 64.4 months and that in the TCM group was not attached (HR:0.68; log-rank $p=0.0006$ ). After propensity score matching, disease-free survival was also significantly improved after TCM with non-TCM (HR: 0.74; log-rank $p=0.02$ ), although mDFS were not attached in both TCM and control group.

In addition, HRs in different subgroups were analyzed in Figure 2. HRs of the TCM group were general lower than those of the control group ( $H R=0.63,0.58$ to 0.67$)$. Among of these, risk of patients in the TCM group were significantly lower than those in the control group in terms of female, no less than 60 years old, rectal cancer, adenocarcinoma, poorly differentiated, stage III disease, receiving chemotherapy, no radiotherapy and no comorbidities $(95 \%$ confidence interval cross the equivalent linear $\mathrm{x}=1)$.

A

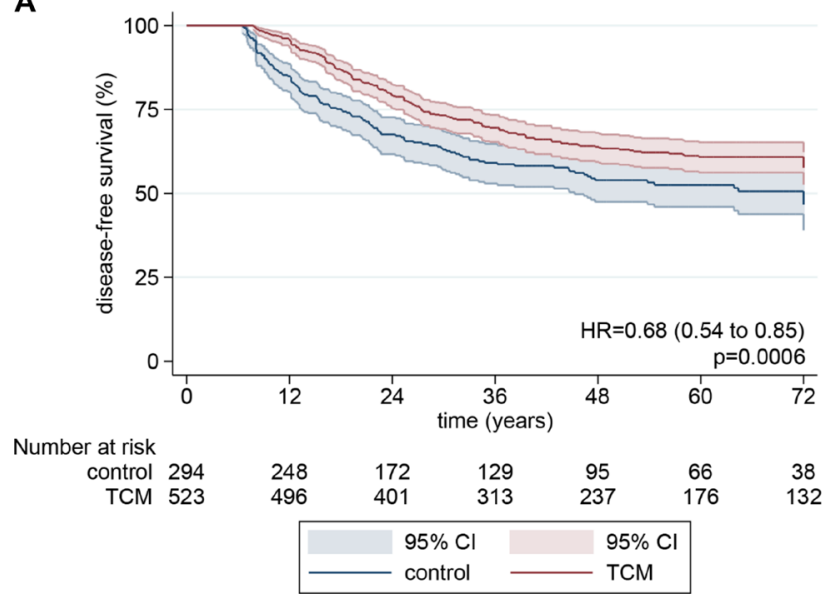

\section{Effect of TCM on different stage CRC patients}

6-year disease-free survival for 137 patients with stage I disease was $79.5 \%$ in the TCM group and $89.1 \%$ in the control group $(H R=1.27, \log$-rank $p=0.65$; Figure 3A). For 353 patients with stage II disease, 6-year disease-free survival was $63.1 \%$ in the TCM group compared with $50.2 \%$ in the control group $(H R=0.72$, $\log$-rank $p=0.054$; Figure 3B). For 327 patients with stage III disease, 6-year disease-free survival was $43.3 \%$ in the TCM group compared with $22.0 \%$ in the control group $(H R=0.47, \log$-rank $p=0.0000 ;$ Figure $3 \mathrm{C})$.

\section{DISCUSSION}

Our data indicate that TCM is independently associated with significantly improved disease-free survival, in particular for patients with stage III disease.

Recently, several studies have proved that TCM can effectively prevent the metastatic recurrence of CRC. A clinical study from Longhua Hospital compared 37 cases in integrated treatment group with 41 cases in western medicine group, and their results showed that TCM treatment is important to improve the outcome of stage II or III CRC in elderly patients [14]. Another two trials from Zhou LY and Xue JZ both indicated that TCM combined chemotherapy could prevent relapse and benefit survival $[15,16]$. Likewise, in terms of DFS, our study proved the significant effect of Chinese herbs on I-III stages patients. However, it is not clear whether the effect of TCM differ in characteristics of patients. Our further subgroup analysis reveal that TCM has a tendency to further reduce the risk of metastatic recurrence in elderly (no less than 60 years old) female patients, and has the same tendency in patients with rectal cancer, adenocarcinoma, poorly differentiation, stage III disease, comorbidities, or chemotherapy. We consider that may be related to the role of TCM in efficacy enhancing and toxicity reducing, improving immunity and quality of life [17-24].

B

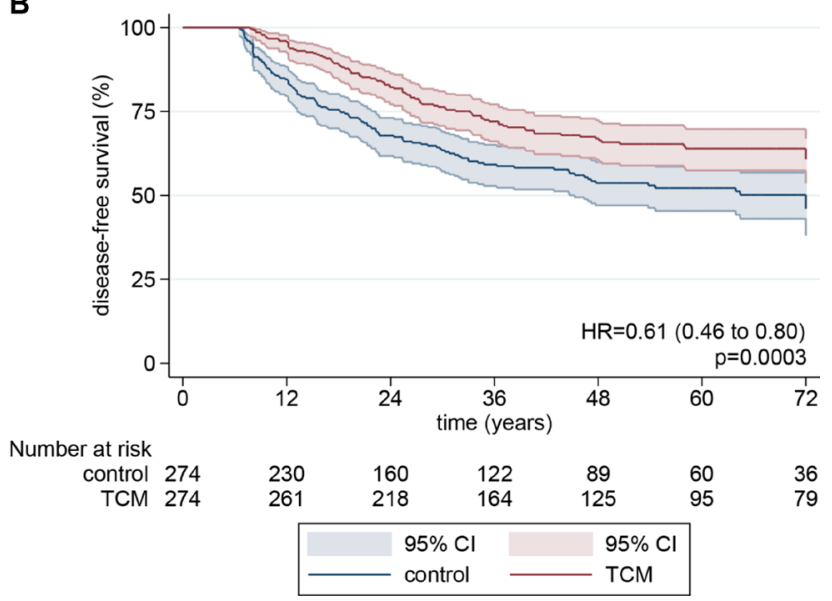

Figure 1: Kaplan-Meier disease-free survival curves for all patients. $P$ values from log-rank tests. Pointwise confidence bands are 95\% CIs. (A) before propensity scoring; (B) after propensity scoring. 
Table 1: Baseline and tumor characteristics of patients before propensity score matching

$\begin{array}{ccc}\text { TCM group }(n=523) & \begin{array}{c}\text { Control group } \\ (n=294)\end{array} & p \text { value }\end{array}$

\begin{tabular}{|c|c|c|c|}
\hline \multicolumn{4}{|l|}{ age (y) } \\
\hline$<60$ & 199 & 97 & \multirow{2}{*}{0.15} \\
\hline$\geq 60$ & 324 & 197 & \\
\hline \multicolumn{4}{|l|}{ gender } \\
\hline male & 274 & 161 & \multirow{2}{*}{0.51} \\
\hline female & 249 & 133 & \\
\hline \multicolumn{4}{|l|}{ location } \\
\hline colon & 312 & 179 & \multirow{2}{*}{0.73} \\
\hline rectum & 211 & 115 & \\
\hline \multicolumn{4}{|l|}{ pathology } \\
\hline adenocarcinoma & 461 & 236 & \multirow{3}{*}{$0.01^{*}$} \\
\hline non-adenocarcinoma & 4 & 2 & \\
\hline unknown & 58 & 56 & \\
\hline \multicolumn{4}{|l|}{ histodifferentiation } \\
\hline poorly & 52 & 29 & \multirow{4}{*}{$0.01^{*}$} \\
\hline moderately & 322 & 149 & \\
\hline well & 17 & 11 & \\
\hline known & 132 & 105 & \\
\hline \multicolumn{4}{|l|}{ TNM stage } \\
\hline I & 85 & 52 & \multirow{3}{*}{0.36} \\
\hline II & 219 & 134 & \\
\hline III & 219 & 108 & \\
\hline \multicolumn{4}{|l|}{ chemotherapy } \\
\hline yes & 420 & 204 & \multirow{2}{*}{$0.00^{*}$} \\
\hline no & 103 & 90 & \\
\hline \multicolumn{4}{|l|}{ radiotherapy } \\
\hline yes & 38 & 17 & \multirow{2}{*}{0.42} \\
\hline no & 485 & 277 & \\
\hline \multicolumn{4}{|l|}{ comorbidities } \\
\hline yes & 270 & 131 & \multirow{2}{*}{0.05} \\
\hline no & 253 & 163 & \\
\hline
\end{tabular}

*statistical difference. 
For patients with stage II-III disease, several studies indicated that adjuvant chemotherapy was necessary for those with stage III disease, but not for all patients with stage II disease, only those at high-risk were more likely to benefit from adjuvant chemotherapy [25-28]. Meanwhile, for patients with stage I disease, adjuvant therapy was not required for them, and they only needed to receive regular colonoscopy. However, it was not clear whether TCM was effective for all patients with stage I-III disease. Our data indicated that TCM had a significant effect on patients with stage III disease, only a tendency on those with stage II disease, and for stage I disease the effect hadn't be discovered. The only other study, which compared 159 in the TCM group and 59 in the control group, reported a similar improved outcome for stage III, but not for patients with stage II disease [29]. We consider it is very possible that the inhibition rate of TCM in lymph node is higher than that in primary tumor, such as 5-FU, VP-16, THP and MMC [30].

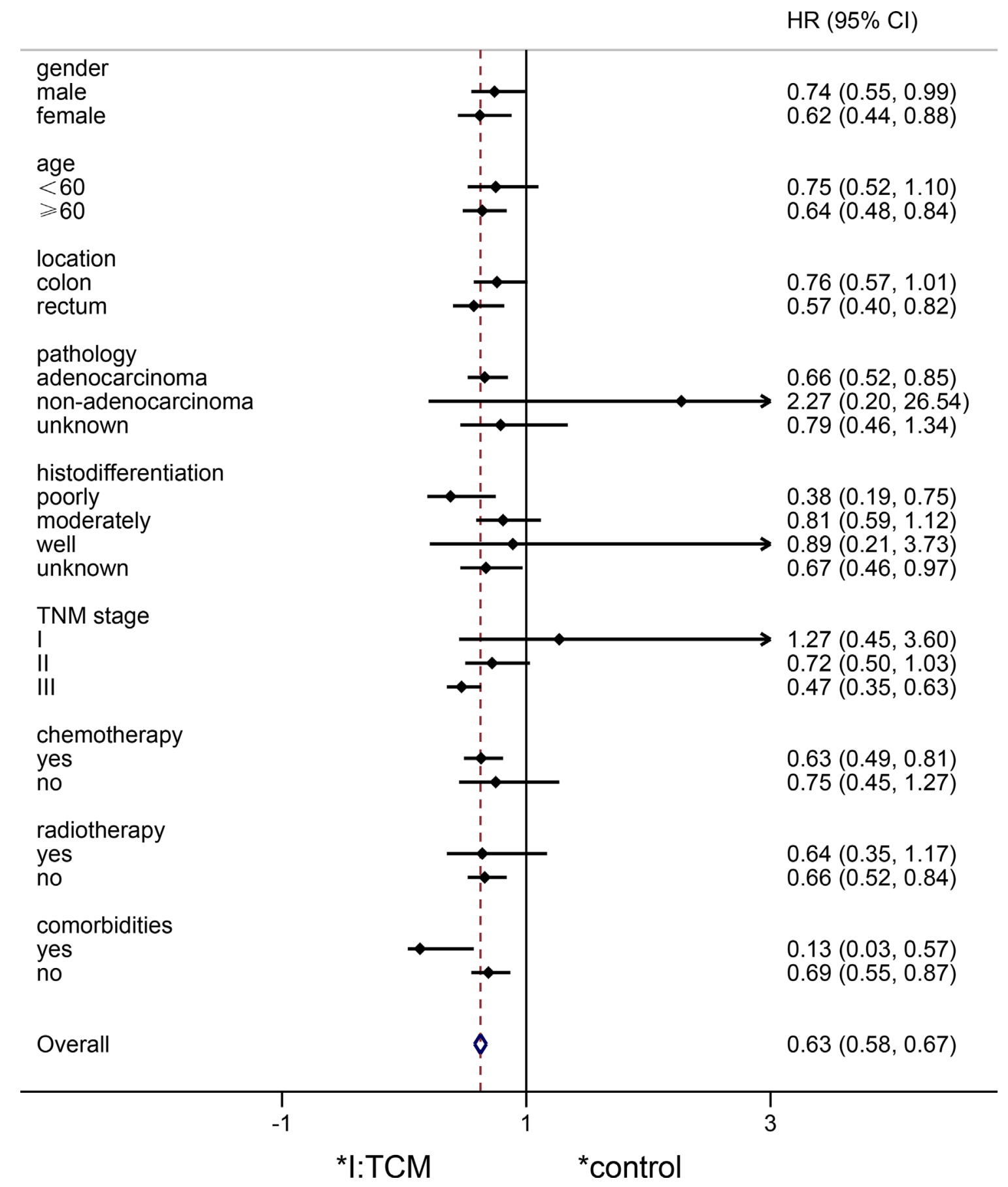

Figure 2: Forest plot of hazard ratio between the TCM group and the control group. 95\% CI did not cross the equivalent linear $\mathrm{x}=1$ means $\log$-rank $p<0.05$; whereas, $\log$-rank $p>0.05$. 


\section{Strengths and limitations}

This is an objective, large sample, research of different effect on I-III stage CRC. Through this research, TCM can be individually used for CRC patients with stage I-III disease, especially for those stage III patients. Meanwhile, one limitation is also in our study. Role of adjuvant therapy for patients with high-risk stage II CRC still remains contention [31-34]. Given margin status, local perforation and bowel obstruction were not sufficient, we thus did not analyse the effect of TCM on stage II patients at high risk.

\section{MATERIALS AND METHODS}

\section{Study design and participants}

The study was a retrospective, multicenter, nonintervention, observational, cohort study involving municipal hospital of traditional Chinese medicine, Shuguang hospital and Yueyang hospital. These three hospitals were affiliated to Shanghai University of traditional Chinese medicine. Research ethics boards from all these three centers

A

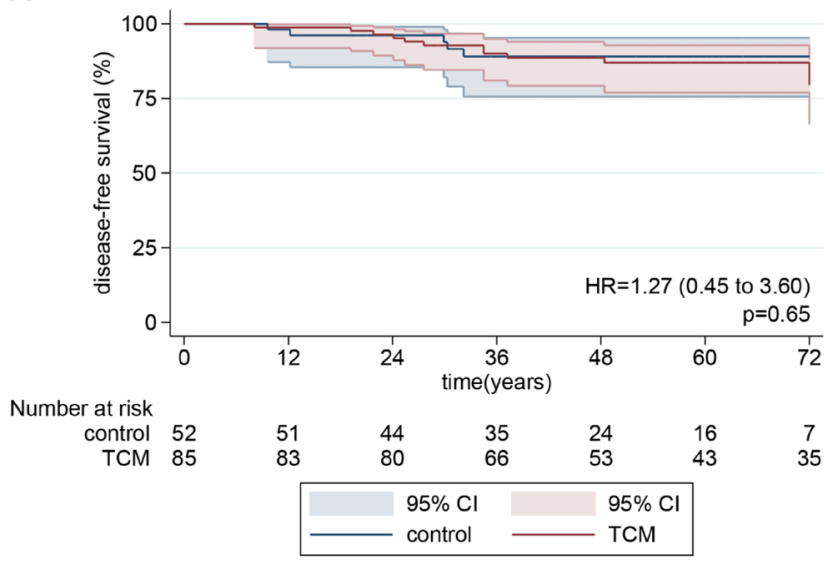

approved the study protocol. Between April 2004 and November 2013, 1019 patients with stage I-III CRC were screened and 819 were enrolled onto the study (Figure 4). Of these, 524 patients were systematically treated with systematic TCM (TCM group) and 295 were not (control group). Notably, systematic TCM treatment was defined as continuously medication more than six months before metastatic recurrence.

\section{TCM treatment}

Traditional Chinese herbs were administrated by decoction, which was suggested to take at least 6 months continuously. One cycle of treatment was defined as 2 weeks. Dosage of herbs were decided by the attending physician according to clinical symptoms of patients.

\section{Data collection}

Clinical data were gathered via clinic appointments or phone by research assistants come from three centers. Variables or outcome included gender, age, location, pathologic type, histodifferentiation, TNM stage,

B

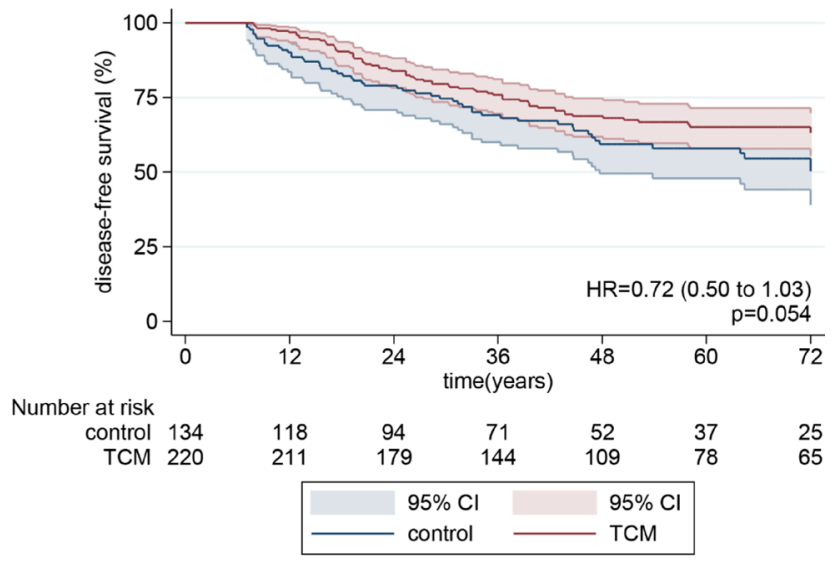

C

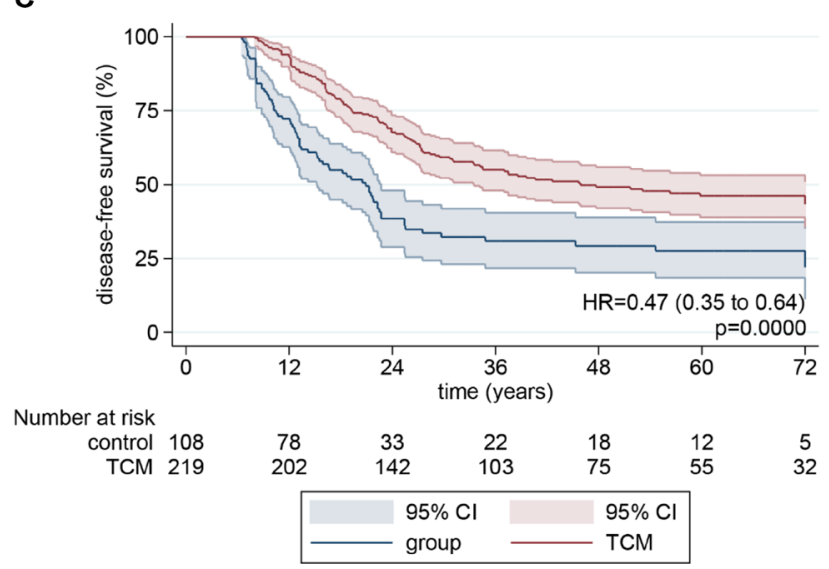

Figure 3: Kaplan-Meier disease-free survival curves for patients with different stage disease. (A) Stage I. (B) Stage II. (C) Stage III. $P$ values from log-rank tests. Pointwise confidence bands are $95 \%$ CIs. 
chemotherapy, radiotherapy, comorbidities, prescriptions of TCM, and status of recurrence or metastasis. Although patients were observed for different amounts of time, data were collected every 6 months postoperatively. The maximum of follow-up was 6 years in order to avoid the possibility of loss in follow-up.

\section{Statistical analyses}

Categorical and continuous variables were respectively analysed by Pearson's $\chi^{2}$ test and Student $t$ tests. Multiple factor analysis was performed by Cox regression. DFS was measured from the date of diagnosis to the date of metastatic recurrence, and was evaluated with Kaplan-Meier curves and log-rank tests for categorical data. Propensity scores were created with logistic regression modeling the probability of a patient undergoing TCM treatment on gender, age, location, pathologic type, histodifferentiation, TNM stage, chemotherapy, radiotherapy and comorbidities. A 1:1 match with random matching order and 0.1 caliper was done, replacement was not allowed. All statistical analyses were performed using SPSS (version 22.0) and Stata (version 12.0). Hypothesis testing was two sided and conducted at the $5 \%$ level of significance.

\section{CONCLUSIONS}

Above all, our study prompt that TCM can generally improve disease-free survival of CRC patients with stage I-III. However, TCM is not necessary for patients with stage I disease, and postoperative patients with stage II disease should be recommended to take 2 years of TCM because most relapses occur within 2 years after

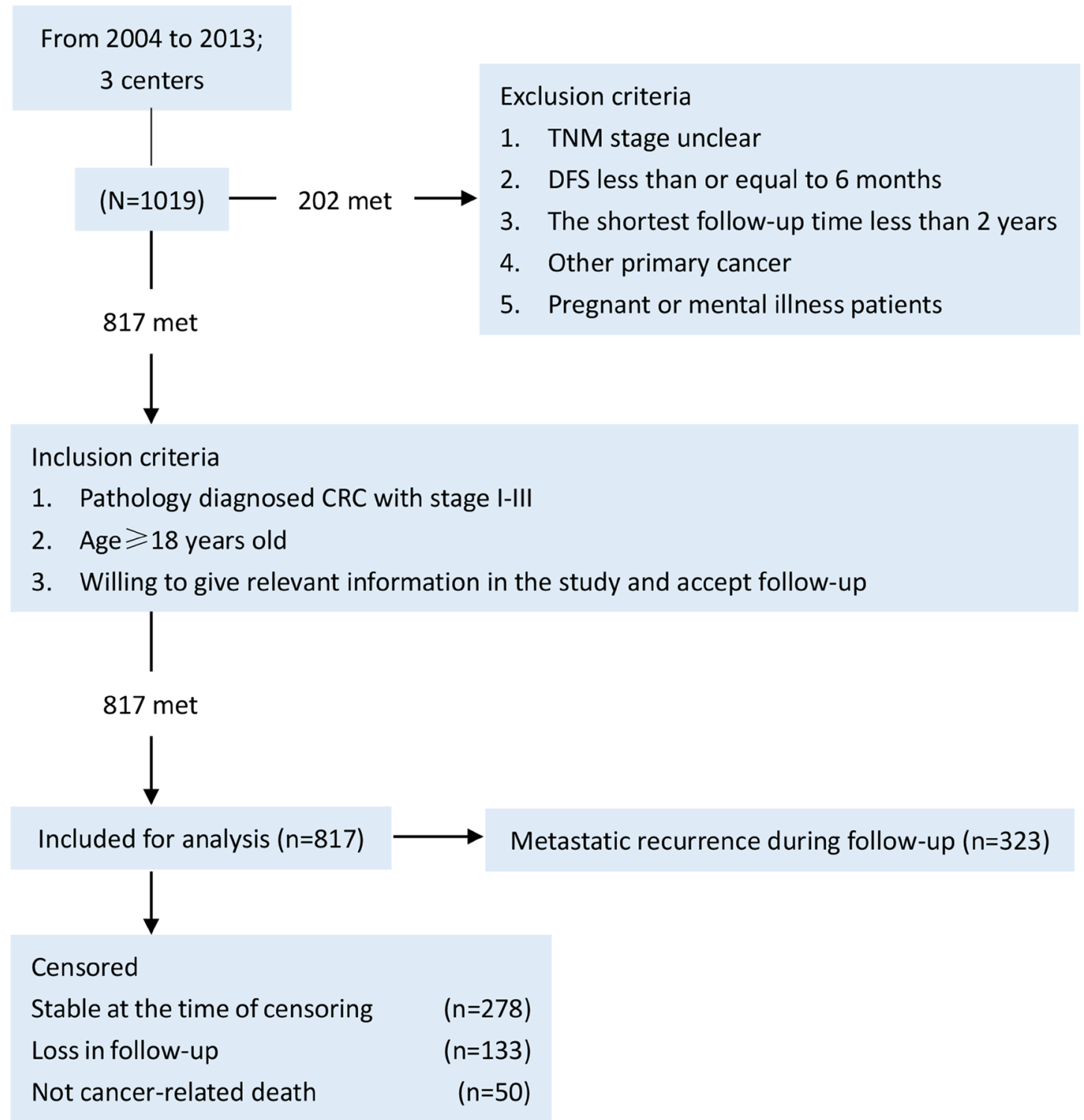

Figure 4: Study patient selection and censoring flow chart. CRC, colorectal cancer; DFS, diease-free survival. 
surgery $[35,36]$. For patients with stage III disease, adherence to medication of TCM during the 6-year followup [37] is worthy of being recommended.

\section{ACKNOWLEDGMENTS AND FUNDING}

Qi Shi's work on this paper was supported in part by the Scientific Research Foundation of Traditional Chinese Medicine of the Shanghai Health Bureau (2014LZ079A), the Scientific Research Foundation of the Shanghai Health Bureau (20134117) and the Scientific Research Plan Project of the Shanghai Science and Technology Committee (14401930800).

\section{CONFLICTS OF INTEREST}

The authors have no conflicts of interest.

\section{STATEMENT OF TRANSLATIONAL RELEVANCE}

Through this study, traditional Chinese medicine (TCM) could be used as an adjuvant therapy for postoperative colorectal patients. For patients with stage II-III disease, clinicians could combine TCM with radiotherapy/chemotherapy to enhance the preventive effect. For patients with stage I disease, TCM could be used to improve the quality of life. In addition, medication duration of TCM could be adjusted according to the TNM stage.

\section{REFERENCES}

1. Siegel RL, Miller KD, Jemal A. Cancer statistics, 2016. CA Cancer J Clin. 2016; 66:7-30.

2. Chen W, Zheng R, Baade PD, Zhang S, Zeng H, Bray F, Jemal A, Yu XQ, He J. Cancer statistics in China, 2015. CA Cancer J Clin. 2016; 66:115-32.

3. Sung JJ, Lau JY, Goh KL, Leung WK. Increasing incidence of colorectal cancer in Asia: implications for screening. Lancet Oncol. 2005; 6:871-6.

4. Wilhelmsen M, Kring T, Jorgensen LN, Madsen MR, Jess P, Bulut O, Nielsen KT, Andersen CL, Nielsen HJ. Determinants of recurrence after intended curative resection for colorectal cancer. Scand J Gastroenterol. 2014; 49:1399-408.

5. Ling CQ, Wang LN, Wang Y, Zhang YH, Yin ZF, Wang M, Ling $\mathrm{C}$. The roles of traditional Chinese medicine in gene therapy. J Integr Med. 2014; 12:67-75.

6. Ling $C Q$, Yue XQ, Ling C. Three advantages of using traditional Chinese medicine to prevent and treat tumor. J Integr Med. 2014; 12:331-5.

7. Hou FG, Shi Q, Wang WB, Chen M, Yu QQ, Ren JL, Li W, Yin PH, Li Q, Hua BJ. Effects of different Chinese medicine treatments on postoperative relapse and metastasis of colorectal cancer: A non-interventional clinical study. World Journal of Gastroenterology. 2014; 22:1890-1896.

8. Hou FG, Shi Q, Liu X, Li HJ, Li W, Liu H, Chen M, Piao SX, Ren JL, Li Q. Effects and status of syndrome and disease differentiation on the traditional Chinese medicine in the treatment of colorectal cancer postoperative recurrence and metastasis. CJTCMP. 2016; 6:2154-2160.

9. Hou FG, Shi Q, Yu QQ, Ren JL, Yin PH, Wang WB, Chen M, Li W, Li LH, Li Q. Effects of different Chinese medicine treatments on postoperative recurrence and metastasis of stage II, III colorectal cancer. Proceedings of National Oncology Conference of traditional Chinese Medicine. 2013.

10. Ge JZ, Yang YF, Xu Y, Liang BY, Luo L, Wu Y, Wu XW, Liu DQ, Zhang X, Song FX, Geng ZY. Clinical analysis of integrative therapy in the treatment of recurrence and metastasis after radical operation of colorectal cancer in elderly patients. Chin J Geront. 2009; :73-76.

11. Yang YF, Xu F, Wu Y. Effect of Quxie capsule on reducing recurrence and metastasis of postoperative colorectal cancer: a double-blind, randomized clinical study. Chinese Journal of Integrative Medicine. 2007; :879-882.

12. Luo L, Yang YF, Li PH, Wu Y, Zhang JW, Wu XW, Gao SD, Liu DQ. Effect of Quxie and Fuzheng capsule on reducing recurrence and metastasis of postoperative stage II-III colorectal cancer: a cohort study. Chinese Journal of Integrative Medicine. 2006; :677-680.

13. YANG YF, GE JZ, WU Y, Xu Y, Liang BY, Luo L, Wu XW, Liu DQ, Zhang X, Song FX, Geng ZY. Cohort study on the effect of a combined treatment of traditional Chinese medicine and Western medicine on the relapse and metastasis of 222 patients with stage II and III colorectal cancer after radical operation. Chin J Integr Med. 2008; 14:251-6.

14. Tao L, Zhu YJ, Lu XM, Gu Y, Zhao AG, Zheng J, Fu CG, Yang JK. Clinical study on survival benefit for elderly patients with resected stage II or III colorectal cancer based on traditional Chinese medicine syndrome differentiation and treatment. Zhong Xi Yi Jie He Xue Bao. 2010; 8:1159-64.

15. Zhou LY, Shan ZZ, You JL. Clinical observation on treatment of colonic cancer with combined treatment of chemotherapy and Chinese herbal medicine. Chin J Integr Med. 2009; 15:107-11.

16. Xue JZ, Wang RM. Effects of traditional Chinese medicine combined with chemotherapy on metastatic recurrence and survival of postoperative colorectal cancer. Chin J Mod Drug Appl. 2016; :259-260.

17. Shi Q, Li W, Le QQ, Chen WT, Ren JL, Li Q, Hou FG. Attenuated effects of Jianpi Qushi herbs on patients receiving FOLFOX4 after colorectal cancer surgery: A meta-analysis. Chin J Integr Med. 2016.

18. Huang CZ, Liu Z, Su Y. Synergistic and attenuated effect of Danggui Buxue Decoction on tumor chemotherapy. Jilin Journal of Traditional Chinese Medicine. 2014; :962-964. 
19. Wei GM. Synergistic and attenuated effect of Renshenyangrong Decoction in the chemotherapy of lung cancer. Chin J Exp Tradit Med Form. 2013; :312-316.

20. Chen HT, Li HF, Song YJ, Liu ZQ, Zhu HX. Sunergistic and attenuated effect of traditional Chinese medicine in the chemotherapy of cancer. Medical research and education. 2012; :70-73.

21. Chen WT, Ren JL, Hou FG, Li Q. Clinical Effects of Colorectal Cancer Patients Receiving Jianpibushen Compound Recipe Combined with Chemotherapy: A Systematic Review. Liaoning Journal of traditional Chinese Medicine. 2015; :1162-1166.

22. Chen WT, Shi Q, Hou FG, Ren JL. Clinical Effects of Colorectal Cancer Patients Receiving Jianpi Compound Recipe Combined with Chemotherapy: A Systematic Review. Liaoning Journal of traditional Chinese Medicine. 2014; :146-148.

23. Chao TH, Fu PK, Chang CH, Chang SN, Chiahung MF, Lin $\mathrm{CH}$. Prescription patterns of Chinese herbal products for post-surgery colon cancer patients in Taiwan. J Ethnopharmacol. 2014; 155:702-8.

24. Wu G, Yu G, Li J, Xiong F. Short term therapeutic effect on treatment of postoperational large intestine carcinoma by Fupiyiwei decoction combined with chemotherapy and it's effect on immune function. Zhongguo Zhong Yao Za Zhi. 2010; 35:782-5.

25. Hutchins G, Southward K, Handley K, Magill L, Beaumont C, Stahlschmidt J, Richman S, Chambers P, Seymour M, Kerr D, Gray R, Quirke P. Value of mismatch repair, KRAS, and BRAF mutations in predicting recurrence and benefits from chemotherapy in colorectal cancer. J Clin Oncol. 2011; 29:1261-70.

26. Gill S, Loprinzi CL, Sargent DJ, Thomé SD, Alberts SR, Haller DG, Benedetti J, Francini G, Shepherd LE, Francois Seitz J, Labianca R, Chen W, Cha SS, et al. Pooled analysis of fluorouracil-based adjuvant therapy for stage II and III colon cancer: who benefits and by how much. J Clin Oncol. 2004; 22:1797-806.

27. Efficacy of adjuvant fluorouracil and folinic acid in B2 colon cancer. International Multicentre Pooled Analysis of B2 Colon Cancer Trials (IMPACT B2) Investigators. J Clin Oncol. 1999; 17:1356-63.

28. Efficacy of adjuvant fluorouracil and folinic acid in colon cancer. International Multicentre Pooled Analysis of Colon Cancer Trials (IMPACT) investigators. Lancet. 1995; 345:939-44.
29. Zhu WR, Zheng L, Lu LL, Guo YB, Chen JX, Ying HF, Shen XH. Effects of Fuzheng Xiaoji stage treatment on the survival of colorectal cancer. Journal of Shanghai University of Traditional Chinese Medicine. 2013; :31-34.

30. Shi XM, Tan BB, Liu XJ, Han J. The relationship between P-gp, Bcl-2, Bax expression and sensitivity to chemotherapy in colon cancer metastatic lymph nodes. Chin J Geront. 2011; :1949-1951.

31. Gray R, Barnwell J, McConkey C, Hills RK, Williams NS, Kerr DJ. Adjuvant chemotherapy versus observation in patients with colorectal cancer: a randomised study. Lancet. 2007; 370:2020-9.

32. Wu X, Zhang J, He X, Wang C, Lian L, Liu H, Wang J, Lan P. Postoperative adjuvant chemotherapy for stage II colorectal cancer: a systematic review of 12 randomized controlled trials. J Gastrointest Surg. 2012; 16:646-55.

33. Schrag D, Rifas-Shiman S, Saltz L, Bach PB, Begg CB. Adjuvant chemotherapy use for Medicare beneficiaries with stage II colon cancer. J Clin Oncol. 2002; 20:3999-4005.

34. O'Connor ES, Greenblatt DY, LoConte NK, Gangnon RE, Liou JI, Heise CP, Smith MA. Adjuvant chemotherapy for stage II colon cancer with poor prognostic features. J Clin Oncol. 2011; 29:3381-8.

35. Sargent D, Sobrero A, Grothey A, O'Connell MJ, Buyse M, Andre T, Zheng Y, Green E, Labianca R, O'Callaghan C, Seitz JF, Francini G, Haller D, et al. Evidence for cure by adjuvant therapy in colon cancer: observations based on individual patient data from 20,898 patients on 18 randomized trials. J Clin Oncol. 2009; 27:872-7.

36. de Gramont A, Hubbard J, Shi Q, O'Connell MJ, Buyse M, Benedetti J, Bot B, O'Callaghan C, Yothers G, Goldberg RM, Blanke CD, Benson A, Deng Q, et al. Association between disease-free survival and overall survival when survival is prolonged after recurrence in patients receiving cytotoxic adjuvant therapy for colon cancer: simulations based on the 20,800 patient ACCENT data set. J Clin Oncol. 2010; 28:460-5.

37. Sargent D, Shi Q, Yothers G, Van Cutsem E, Cassidy J, Saltz L, Wolmark N, Bot B, Grothey A, Buyse M, de Gramont A; Adjuvant Colon Cancer End-points (ACCENT) Group. Two or three year disease-free survival (DFS) as a primary end-point in stage III adjuvant colon cancer trials with fluoropyrimidines with or without oxaliplatin or irinotecan: data from 12,676 patients from MOSAIC, X-ACT, PETACC-3, C-06, C-07 and C89803. Eur J Cancer. 2011; 47:990-6. 